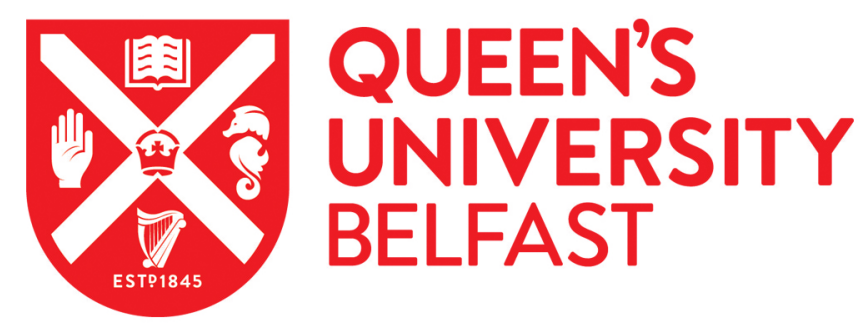

\title{
Breaking the Intimate Screen: Pre-Recording, Special Effects and the Aesthetics of Early British Television
}

Johnston, D. (2015). Breaking the Intimate Screen: Pre-Recording, Special Effects and the Aesthetics of Early British Television. Critical Studies in Television, 10(3), 53-66. https://doi.org/10.7227/CST.10.3.5

Published in:

Critical Studies in Television

Document Version:

Peer reviewed version

Queen's University Belfast - Research Portal:

Link to publication record in Queen's University Belfast Research Portal

Publisher rights

@ 2015 Author(s). Published by Manchester University Press

\section{General rights}

Copyright for the publications made accessible via the Queen's University Belfast Research Portal is retained by the author(s) and / or other copyright owners and it is a condition of accessing these publications that users recognise and abide by the legal requirements associated with these rights.

Take down policy

The Research Portal is Queen's institutional repository that provides access to Queen's research output. Every effort has been made to ensure that content in the Research Portal does not infringe any person's rights, or applicable UK laws. If you discover content in the Research Portal that you believe breaches copyright or violates any law, please contact openaccess@qub.ac.uk. 
Breaking the Intimate Screen: Pre-Recording, Special Effects and the Aesthetics of Early British Television Drama

Derek Johnston

\begin{abstract}
In his seminal study of early British television drama Jason Jacobs emphasises the importance of the concept of 'intimacy', during the period from the beginning of regular BBC television broadcasts in 1936 to the arrival of competition in 1955. This article focuses upon the role of special effects in breaking free from the restrictions of the studio, showing that effects were not only of use in expanding the temporal and spatial scope of television drama, but were also considered to be of interest to the audience as a way of exploring the new medium, receiving coverage in the popular press.
\end{abstract}

Key words: live drama; BBC; special effects; pre-recording; audience

In his seminal study of early British television drama, Jason Jacobs emphasises the importance of the concept of 'intimacy' to television drama during the period from the beginning of regular BBC television broadcasts in 1936 to the arrival of competition in 1955. As producers demonstrated a desire 'to "get in closer" to the dramatic action, to become intimate with it' (Jacobs 2000,6), critics and producers also considered intimacy in terms of productions' appropriateness for reception in the 'intimate' domestic sphere of the home. The drive was also in part a response to technical limitations, including the restrictiveness of Alexandra Palace, with 'only two studios, measuring seventy feet by thirty feet' (Pudney 1948, 11). Although 'intimacy' was not the only concern for television drama (and indeed, Jacobs [2000, 7] highlights that the concept was mobilised partly to separate drama 'from the 
more macho observational knowledge of the public sphere that television's Outside Broadcast abilities could provide'), closeness was part of an attempt to develop a style for television drama that would set it apart from film, theatre and radio. Television in this early period was a site of near-constant experimentation. Especially in the years before 1951, when the small audience and a sense that this was still an experimental service provided the opportunity to try out different approaches to making television drama.

This article focuses on the role of special effects in breaking free from the restrictions of the studio, showing how they were used not only to expand the temporal and spatial scope of the drama, but also considered to be of interest to the audience as a way of appreciating the new medium. Special effects included pre-recorded film inserts and narration, multiple sets, model work and animation, each of which was combined with the live studio performance. Drawing upon archival research including original scripts as well as audience responses and the popular press coverage of television at the time of broadcast, this article deals mainly (although not exclusively) with telefantasy. This broad genre, which incorporates all nonrealist television, offered particular opportunities for utilising effects in ways that seemed appropriate for experimenting with the new medium of television and its narratives forms. As shown later, while drama was a key area of production that offered particular opportunities to experiment with the possibilities of the medium, these also extended into other forms of programming, eventually used more in light entertainment than drama.

While the dramas discussed here may have been unusual, and consciously experimental in some cases, they should also be considered in context. From its start in the thirties until the early 1950s, television in the United Kingdom was a minority interest, although one which grew quite rapidly in popularity and reach. Along with Selwyn Lloyd's minority report that recommended the abolition of the broadcasting monopoly, the 1951 publication of the Beveridge Committee's findings marks the realisation that competition in 
broadcasting was not only possible but being actively sought, with the result that the BBC had to professionalise its services in order to retain its position. The pride in being the first nation to develop regular television broadcasting was fast disappearing as overseas broadcasters overtook the United Kingdom, both technologically and in business terms. This perceived challenge to the BBC's position led to the approval of further funds to develop the television service from 1948 onwards, but this increased emphasis on the medium also meant more scrutiny of the service and its management.

In 1953 television was available in most parts of the country, with the BBC estimating that 80 per cent of the British population could receive it by December 1952 (Hunter 1952, 5). The number of people from across the social and economic spectrum willing to buy or rent grew rapidly, with 1.7 million television licences issued by October 1952, out of a population of 50.2 million (ibid.). A television set at the time cost around 70 to 80 guineas (ibid.); and with average earnings at $£ 400$, the cost represented nearly a quarter of an annual wage. This suggests that, while it had grown swiftly, the actual audience for television remained fairly limited as a section of the overall population, at least in part due to the cost of acquiring a TV set. However, this issue was partially offset by the opportunity to rent, spreading the cost while allowing for what producer Jan Bussell referred to as the 'snobbery of possessing a television set' $(1952,12)$, facilitated in the post-war period by the gratuities issued to those demobilised from the military.

The BBC's understanding of its developing audiences in the face of competition is also central to this article, as it influenced the approaches taken to the medium. Indeed, the BBC began to undertake audience research from early in its history, beginning with a simple viewer survey in 1937, but developing more comprehensive ones in autumn 1948 and December 1950. The analysis of the results published in BBC Quarterly in 1950 and 1952 demonstrate that the Corporation recognised that its programmes were now watched by a 
broader cross-section of the population, beyond the wealthy middle-class 'early adopters' of the 1930s. Indeed, in 1952 Robert Silvey, Head of Audience Research, commented that 'television was already spreading “downwards” through the social pyramid’ (1952, 31), with the result that producers such as Bussell felt excluded from programme planning as heads of departments took over in an attempt 'to cater for a new viewing public' through 'the deliberate lowering of the intellectual standard of programmes' $(1952,12)$. While this is the anecdotal opinion of a single producer, it does indicate a tension between creative personnel's desire to develop the medium and the BBC management's perceptions of the changing audience as tending towards aesthetic conservatism.

\section{Breaching Temporal and Spatial Limitations}

Television drama producers sought to use the known technology of film to supplement the new technology of television early in its history. The BBC Television Service officially began on 2 November 1936, after a period of experimental broadcasts. Even the official opening night of the BBC Television Service in November 1936 drew on the technology of film to make possible what was desired, with the broadcast of the BBC film, Television Comes to London. This showed the construction of the facilities at Alexandra Palace, the making of cameras, and other aspects of the preparation for the launch of the Television Service. The technology ofBy producing this on film allowed-the production-BBC was able to record and then to compress the period leading up to the launch into 15 minutes, using optical wipes, superimposed scrolling text and relatively fast editing to music that would not have been possible in television of the time. The film ends with the performance of a song celebrating those 'magic rays of light / That bring television to you' being transmitted to households shown watching the performer on their television sets, but the majority of the film is concerned with the industrial and technical effort required for broadcast. In other words,
Commented [JA1]: To avoid the repeititon of 'technology' could we say, 'the limits of televsion'?

Commented [DJ2]: I was setting up an opposition between 'known' and 'new' technology.

Commented [JA3]: Why 'Even'. Sorry but I'm getting muddled with your use of 'experimental'

Commented [DJ4]: 'Even' because they could have focused on showing what was different about television, but instead relied on film for some of what they wanted to achieve.

Commented [JA5]: Sorry to sound dim, but I don't quite get this sentence. Are you saying this was a prerecorded film

Commented [JA6]: It's this part of the sentence which I don't quite get. Can it just be deleted. Are you trying to say, that while the film is about illusion, the programme had been around demysterifying the process?

Commented [DJ7R6]: Revised; could be subdivided into two sentences at 'but' if that would be clearer 
while the film may conclude with a presentation of television as being a magical form of domestic entertainment, it is, while atmospheric, primarily concerned with demystifying television, emphile empising through its images and the use of music that this was a great achievement of technological prowess and effort. However, the need to use film to present this material in quite this way demonstrated the restrictiveness of the television technology, itself unable at the time to record the preparatory work or edit at a pace.

Less than a year after opening, on 20 September 1937, Below the Surface, A Naval Play incorporated extracts from the silent film, Under the Surface (BBC PAB). Eight days later, the play, Turnaround, used film sequences of a liner docked at Southampton (BBC PAB). The 6 December 1937 adaptation of Once in a Lifetime emphasised the distances covered in the play with footage of train wheels, together with a film 'extract from "Secrets of Hollywood" and "Aeroplanes in flight"' in its expansion of the space of the play production beyond the restrictions of the studio (BBC PAB). By the end of its second year, BBC television drama was already drawing on a number of sources for filmed inserts to expand the physical and temporal scope of its productions, including adapting existing film material, using specially recorded footage and drawing on stock footage. Indeed, the end of 1937 was marked by From Alexandra Palace: 1936-37, described in the Radio Times as, 'An attempt to re-create - or at least to remind you of - some of the outstanding events in television since the first programmes were transmitted from Alexandra Palace in August 1936' (Anon 1937, 28). This programme incorporated various segments from the Film Library. The idea statement that these events were recreations and prompts to memory makes it clear that it was not the performances that were filmed. However, the re-use of the film elips in these in its re-stagings of earlier performances and events, which demonstrates that they film elements were considered to have played key parts in this first year of broadcasting.
Commented [JA8]: Too many 'whiles' . Could the sentence be simplifed.

Commented [DJ9R8]: revised

Commented [JA10]: Can you take another look at this sentence. It's not clear: is the footage of train wheels an extract from Secrets of Hollywood, or is this another extract. Plus there are too many 'the plays'

Commented [DJ11R10]: Revised

Commented [JA12]: Apologies for being utterly dim but don't understand what you're trying to say in the sentence. Can it just be cut and we move to the next sentence with something like, 'Given that the reused film clips made it into the programme suggest that the borrewed elements were considered ...' (Plus, if television was live and not recorded, surely the reuse of these film elements was all they had left? Just a question. 
Such aThe view that use of film was important in television production was not universally popular. For some, innovation lay in finding the 'true' form and style for television, which defined its difference from related media such as cinema, radio and the theatre. One of those who saw filmed insert as inappropriate was drama producer Jan Bussell, who believed that,

Film and television are quite different media and to borrow is a confession of weakness. Television should rejoice in its limitations, and exploit them. I have always found that the removal of limitations in any medium tends to destroy art. After all, there is no art in showing the real thing. What is shown should be interpretative - a comment on reality. (1952, 55).

Bussell is calling for a consistency of style. Given that television was unable to offer the same level of perceived realism as film, he also assumes that the use of a filmed insert would prove disruptive for viewers, simply because they would be unable to tell a change in the origin of the visual material broadeasttaking them out of their engagement with the television drama by introducing a different visual register that is recognisable as belonging to film. This does not mean that Bussell rejected film inserts entirely; he certainly made use of them in his 1938 adaptation of R.U.R., where inserts were used to provide on-screen advertisements for the Rossum's Universal Robots of the title (BBC WAC T5/443, R.U.R., 3 February 1938). ${ }^{i}$ However, as the inserts were presenting diegetic filmed advertisements, the use of film in the production and the associated change in visual style was, in Bussell's opinion, aesthetically justified as well as serving a practical purpose.

Such shifts between television and film were recognisable due to the different production requirements and practices of the two media and subsequent impact on visual
Commented [JA13]: Can I suggest 'a re-use of film extracts'

Commented [JA14]: Apologies, but is Bussell saying this.
It seems to me that what he's say is that television should
embarrass its limits and find creative ways around them. If
film and television are interpretations of reality, television
should find its own way of interpreting rather than borrowing
from film. Sorry to interject, but this is what he seems to be
saying.
Commented [DJ15]: This sentence does not make sense,
and is not mine. Bussell actually says that the problem is that
the audience can tell the difference between film and
television.
television. 
style. Because film is set up for a single shot, each can be planned and produced in detail to support an intended effect and reshot to resolve any problems or simply to offer alternatives that may be selected in the editing process. Television, on the other hand, was performed live with no opportunity for editing beyond a fade between shots, with fast cuts between cameras only becoming available in the post-war period (Jacobs 2000, 46), and its relatively low resolution and contrast initially presented a limited depth of field. When inserts were used, the film image was projected onto a screen and re-captured by the television camera, a technique known as 'telecine'. This process meant that the final broadcast image had the qualities of a television one in terms of resolution and contrast, but retained the depth of field of the initial filmed sequence, along with the mobility of camera, fast editing and the ability to take extreme close or long shots not possible, or particularly clear, with early television cameras.

The majority of filmed inserts were used as establishing shots, but sometimes provided close-ups of a prop like a letter to increase the intimacy of presentation. Such shots were not achievable with the early television cameras or within the limitations of live broadcasting; for example, a close-up of a prop would require the camera to come in so close that it would necessitate any switch to a wide shot from another camera mich-would most likely show the initial camera. Some productions used separate insert cameras on separate reproduction sets to avoid this problem, but this meant using up more studio space and resources and added to the complexity of the logistics, such as moving cameras around the studio, just to achieve one brief shot. Inserts thus resolved the spatial limitations of the live studio drama, as well as operated as transitions that allowed for equipment and actors to move between sets, accommodating costume changes and make-up. While such uses of film inserts to breach the temporal and spatial limitations of live studio drama may not always have been seen as fitting with the particular qualities of television, they were used often early 
on, incorporated into the various programmes cited above, including Below the Surface (1937). This suggests that the normal aesthetic for early television drama was a hybrid of film and television, with the use of inserts to provide establishing shots of locations similar to film, rather than associating television drama with the protocols of theatre.

Drawing on film technologies and expectations generated by filmic rather than theatrical traditions, these techniques for expanding the possibilities of live studio drama could also be found into other forms of programming. Holiday in Berlin (1952), for example, applied the technique of back projection, a practice used earlier in the television version of Michael Howard's comedy show, Here's Howard (1951), musical revue recreating acts of the past The Passing Show (1948-53), as well as Children's Hour (Anon. 1951, 40). This might suggest that experimentation with new effects had already been 'relegated' to variety and children's programming, rather thanwith the possibility of using them in '-sserious' adult programming at a later date once the techniques were mastered. Although-With specific reference to back projection, though, Gerard Tyrrell $(1952,10)$, external script reader to the BBC TV Drama Department, claimed that the delay in its introduction was due to the restrictions on studio space more than anything else. Back projection also provided an easier option than the modification of the studio space. For example, the 1949 production, The Gentle People, utilised a large water-filled tank in the studio; the potential problem with this approach appear in reports recounting what happened when the tank cracked because the weight, resulting in water leaking through into the transmitter room beneath (Norden, Harper and Gilbert 1985, 65-66).
Commented [JA17]: Sorry to intervene, but I thought The Passing Show was a muscial revue, which by its title suggests songs and performance from a past season. You don't need to say 'recrating acts ..'

Commented [DJ18]: Going by the Radio Times listings,

'The Passing Show' was a musical review, but it was a

historical one looking at preceding decades rather than

relating just to the past season.

Commented [JA19]: Why 'relegated'? This feels as if a step has been missed and I don't understand why these technologies have been dowgraded.

Commented [JA20]: Apologies for coming across as completely dense, but the time line is muddled. You're saying that back projection was relegated to variety, before it's been introduced into drama. This seems rather back to front.

Commented [DJ21R20]: Amended version is hopefully clearer

Commented [JA22]: This paragraph is rather packed, it has moved from film techniques used in other genres, to back projection as an answer to restricted space and onto an example of the cracked tank, which doesn't have seem to have anything to do with back projection. .

\section{The Spectacular Screen}


While the uses of effects were to overcome the temporal and spatial limitations of live studio production, others were more straightforwardly spectacular. The visual display was itself about the possibilities of television. Sometimes this meant emphasising how the restrictions had been overcome and breached the norms of television aesthetics of the time. This was the case with many experiments in documentary television which sought to show life beyond the confines of the studio, whether in a submarine, at a race course, through a telescope, down a microscope or even overseas. However, this attempt to provide visual engagement also extended to drama and light entertainment. This section will examine some of the techniques used by drama producers to create visual appeal, as well as how press reviews engaged with the aesthetics as something of interest to viewers.

On 13 January 1938, a reviewer for The Daily Telegraph described the problem of the television camera as follows: its 'field of vision is so small that only "close-ups" are really effective. Two figures fill the foreground - three have to squeeze to get in’ (Darlington 1938, n.p.). However, only the technology was developing rapidly. Only four days later a reviewer for The Times reported:

A year ago, when the new machine was only feeling its way across an unknown field of entertainment, it could manage only the close-up, in which nothing of the background was visible, and the full scene, in which the figures were often so minute as to be more or less meaningless. To-day it effects a compromise between these two extremes: it joins close-up and general scene, and it adds to these that shifting knowledge of a room or place and the people in it that one gets when a film camera slowly traverses a scene. (Anon. 1938, n.p.).
Commented [JA23]: I don't quite understand the use of the word 'breach'. You mean they caused a rupture in the norms of TV aeshetics, right?

Commented [DJ24]: 'to breach' does mean 'to cause a rupture'

Commented [JA25]: Can you modify the tone. This suggested that the problem was solved in 4 days. 
This suggests that television was developing new ways of approaching visuals that were not restricted to a choice between close-up or wide shot, but able to provide a stronger sense of the interconnectedness between shots and the positioning of specific individuals within the overall space. However, the disparity between the two reviewers and their ideas of what television could do also suggests that the success of these new techniques was somewhat dependent on personal taste and the degree of the usage.

While Jan Bussell had experimented as early as 1939 with using only a subjective camera for the play, Condemned to be Shot (Caughie 1991, 34), this technique was also integrated into the 1950 adaptation of The Strange Case of Dr Jekyll and Mr Hyde. Here it formed part of the adaptation's emulation of the documentary approach of the original novel. When Utterson (Jack Livesey) relates his first encounter with Hyde (Desmond Llewelyn), the script notes that 'the camera has become Utterson' (Cross 1950, 15) and retains this firstperson point of view throughout the encounter with Hyde. It only breaking into a third person viewpoint when Utterson is invited into Jekyll's house and he walks past the camera, leading to a new scene. A brief, pre-recorded voice-over leads into the first-person sequence, allowing Livesey to move into position for the next scene. The voice-over articulates his thoughts, his intention to encounter Hyde, before the actor provides Utterson’s live dialogue in the following scene.

The dramatic, as opposed to practical, purpose of the point-of-view camerawork is to give more impact to the sight of Hyde’s face. While the production opens with the spectacle of Jekyll's (played by Alan Judd) transformation into Hyde, only his profile and hairy hands are initially seen. As Bussell notes, with 'the television close-up [...] the artist is brought to your fireside just the size he would be if he were really sitting there' $(1952,20)$. The shock of introducing an 'approximately actual size’ (ibid.) Hyde into the viewer’s living room, looking directly at them through the subjective camera, draws on the intimacy of television to engage 
directly with the viewer at a base level. Camerawork and intimacy combine to demonstrate that the spectacular was possible without resorting to filmed inserts.

Such use of the possibilities of television attracted interest from the press media. A reviewer for The Sketch awarded their regular Critic's Choice to 'Fred O'Donovan: For his particularly exciting production of The Strange Case of Dr. Jekyll and Mr. Hyde. In this, his one-camera technique generated an almost unbearable tension, especially in a brilliant tracking shot through two rooms' (Butcher 1950, 569). The review in The Star not only praised the transformation scenes, but explained that they were achieved 'sometimes by quick moving of Alan Judd (Dr Jekyll) and Desmond Llewelyn (Mr Hyde) and sometimes by superimposing the images of two cameras' (sic., Anon. 1950, n.p.). While not all reviews were as positive, many demonstrated an awareness of the producer and his particular style and most Most of these reviews considered the technical possibilities of television with regard to this particular story, whether or not they thought those possibilities had been successfully realised.

This assumed interest in television technique on the part of the general public was also demonstrated on 21 November 1948, when the Sunday Graphic and Sunday News ran an article explaining the effects used in a production of Blithe Spirit, which included a translucent ghost sharing the same space with 'solid' characters and environment. The article outlined the technical use of plate glass and a mirror to overlay the image of the 'ghost' onto the live television image, including a diagram explaining the relevant angles. Two photographs show elements of this setup, including a wide shot of the camera with its ghost equipment, and another focussing on the floor marks which told Betty Ann Davies, playing the ghost, where to stand for the effect to work. A third behind-the-scenes photograph showed a shot largely as it would appear on the television screen, incorporating both solidseeming characters and the translucent ghost, but also including the television camera (Anon.,
Commented [JA26]: Can we have a 'sic' as this isn't grammatically correct: 'sometimes by quick moving of Alan' $\cdots$

Commented [JA27]: Repetition of 'possibilities' Commented [DJ28]: This is to make it clear that this phrase is referring back to the previous clause and particularly the idea of the possibilities of television. 
1948a, n.p.). The same photograph was used in an article on the drama that appeared in the Psychic News, where it is identified as a 'composite picture'. The focus was once more on how the production achieved the ghost effects, with emphasis placed on the effectiveness of depicting a spirit rather than on how it was done. Intriguingly, this article points to earlier uses of similar technical effects, stating that this production's techniques 'seemed an improvement on methods used previously' that had a 'watery wraith-like appearance which has sometimes marred earlier psychic productions' (Anon., 1948b, n.p.). Interest in television technique thus appears to have been present across a range of publications appealing to a number of different audiences.

Such press coverage has also provided a useful visual record of one of the more spectacular experiments in early television form, the 1949 adaptation of H.G.Wells' The Time Machine. This production was a concerted effort to expand the boundaries of television in terms of visuals and storytelling, incorporating key elements of the novel, ranging from the Victorian period to the end of life on Earth in the far distant future. The BBC's own promotional material in the Radio Times considered the difficulties of this adaptation, picking up on the description of the production as a 'visual experiment' by its producer, Robert Barr (The Scanner 1949, 24). The picture magazine, Illustrated, ran a three-page article between the first performance and its repeat, outlining some of the techniques and providing a sense of how the production had responded to criticism. But the emphasis of the article is on the images, which reproduce studio shots from the production as well as behind-the-scenes material. This includes an explanation of how two images are merged to provide the impression of a forest fire in a shot incorporating the performers, as well as reproductions of the images used in the extensive and ambitious time travel sequence. This involved studio performance, pre-recorded music and voice-over, pre-recorded film elements, such as a clock with its hands spinning rapidly and a futuristic landscape in the rain, as well as the use of 
painted images merged with the live material to show the Time Traveller's (played by Russell Napier) journey into the future. It lasted for approximately three minutes, out of a total planned running time of 60 minutes, indicating that it was intended as a particularly important part of the production, and an aspect that was explicitly spectacular, in the sense of something to be looked at (Barr 1949, 11).

The production space was opened out several times using still pictures to provide wide shots of locations. In addition, the script called for an unusual vertical expansion of space, during a sequence in which the Time Traveller descends a shaft, encounters Morlocks underground and flees back to the surface. Telecine shots alleviated the need for certain effects to be created live in the studio. In this production, telecines included the glowing eyes of the Morlocks, shots of rain and fire, and a further time travel sequence as the Time Traveller moves further towards the end of the world, where he is menaced by ' 1 crab's claw. Practical, and as large as possible' (ibid,, iii). This is followed by a scene of the slow death of the planet, the sun going down for the last time and eternal snow settling through use of telecine superimposed on a dark soundstage (ibid. 28).

Where Bussell deployed effects and editing decisions according to the fantastic demands of the script and his own desire to push the possibilities of what television, could do. Barr expanded settings in a more naturalistic mode. Indeed, one Radio Times article described his approach as 'drama-documentary', indicating a fictional approach which utilises the aesthetics of the real (The Scanner 1949, 24). To achieve this sense of realism it was essential to engage in a range of trickery to breach the temporal and spatial restrictions of live television. Barr's frequent use of establishing long shots suggests a cinematic influence, and the number of locations used also indicates that he was interested in showing that television could handle the spatial scope of the production as well as its concepts. Indeed, the sequence involving the vertical shaft has no real narrative function, but simply broke away 
from the perceived restrictions of studio space by demonstrating depth. A more original approach to the use of film inserts was taken by utilising them within scenes. Lez Cooke claims that such adoption were part of what makes Rudolph Cartier's Nineteen Eighty-Four 'such an innovative production' (2013, 9). Its use in The Time Machine five years earlier indicates that the technique was being experimented with, even if Cartier's later production managed to utilise it more smoothly and in a more engaging way.

However, this experimentation did lead to problems with the production, and was not well received by all, with one viewer complaining that 'it was so weird and impossible that I could not get the least bit interested in it and felt quite relieved when it was over' (Wrench 1949, 25). In examining the available material on the science fiction productions that followed The Time Machine, it is noticeable that only The Strange Case of Dr. Jekyll and Mr. Hyde seems to have undertaken any attempt at innovative or striking visuals before Rudolph Cartier's take on the genre with The Quatermass Experiment in 1953. There were certainly those who attempted to rein in Cartier's visual expansiveness, including Michael Barry as Head of Television Drama (Jacobs 2000, 134). However, it is notable that his expansion of the intimate screen and re-engagement with the possibilities of the medium, including the new possibilities that had come about through technical advances and the development of the BBC's resources, occurred at a time when the BBC Television Service had become aware of the distinct possibility that a rival television service would launch. Indeed, Cartier joined the BBC in 1952 (Jacobs 2000, 130), the same year that the Radio Times reported plans, following the Beveridge Report, for 'the setting up of new Television stations in competition with the BBC, with the approval of Parliament, when the economic resources of the country permit' (Anon. 1952b, 2). This suggests that there was some attempt to reinvigorate the television service, its aesthetics and programming in order to engage with the expanded actual and potential audience and demonstrate that the BBC was fit for purpose. 


\section{The Changing Audience}

The previous section has provided some examples of how the viewer was addressed in the press coverage of television in relation to potential interest in visual and other aspects of production. Of course the audience cannot be considered a monolithic body of homogenous tastes and interests, and the various reporting publications have different inflections reflecting those of their readerships. For a photographic news magazine such as Illustrated or Picture Post, an interest in a visual medium is to be expected, particularly at a time when a significant part of the population could only read about this intriguing new development, not yet able afford a television set, or necessarily receive the signal even if they could. While they would ultimately compete as providers of visual information and entertainment, the illustrated magazines arguably contributed to the spread of awareness of, and interest in, television, its personalities and programming.

There was a significant shift in the composition of the viewing public from the launch of television in 1936 to the mid-1950s. The earliest television audiences showed a distinct preference for 'high culture' programming and distaste for those of a practical nature. In a 1937 BBC enquiry into Viewers and the Television Service, 'Disapproval concentrated largely upon demonstrations of cooking, washing, ironing, etc., which were condemned as of little interest to those who could afford television sets' (Listener Research Section 1937, n.p.). Later audience research and letters to the Radio Times and other publications suggested a far broader taste. They also reveal a range of uses to which television was put: education, information, and entertainment and relaxation.

As the comments of Bussell illustrate, there was an early prejudice against realism in television drama amongst certain critics and producers. Realism was portrayed by these people as too easy, and as not being suited to television, which should instead be making the 
most of its own characteristics of intimacy and suggestion. However, the argument against realism was in many ways one against cinema, particularly films seen as a sop to the masses and not for the educated, metropolitan audience, who were assumed to receive television (because of their London location), but also able to afford the sets in the first place. Indeed, the New Statesman and Nation reviewer of Dallas Bower's 1938 dual-cast (off-screen singers and on-screen actors) production of Tristan and Isolde states 'that film producers, especially those of news films and films of actual events, are complete morons catering for half-morons' (Turner 1938, n.p.). Here it seems that it is the spectacle of actuality that is decried, and the appeal to sensation, where needing to use the imagination and interpret material appropriately is seen as more valuable.

Cultural snobbery does not just run in one direction. The Socialist Daily Worker considered the state of television in 1947 and suggested that 'this new working-class audience will be extremely critical and demand a much higher standard of entertainment, dramatic art, and educational programmes than has hitherto been thought possible' (Television Expert 1947, n.p.). It takes the position that the 'nice' programmes presented to the viewers did not have sufficient complexity to serve a working-class audience, and suggests that these visions of comfortable upper or middle-class life and associated forms of entertainment such as cabaret, ballet and opera were not substantial enough for the viewer who wants to make the most out of their investment in television. Indeed, Mass Observation research from 1949 into attitudes towards television showed that most respondents wanted 'more outside broadcasts, [...] more television of respectable record [...] where TV simply seemed to replace the eye at the live event' (O'Sullivan 2007, 166). Such evidence suggests that this concept of television as the educational relay was quite widespread. Tim O’Sullivan contends that these responses were spurred by other concerns about the acquisition of a television set, leading to the disappearance of other leisure activities considered of greater

Commented [JA32]: Okay, I'm sorry but this session stil isn't working for me. Isn't this about taking the viewers into spaces they might not otherwise have access - Wimbledon, the FA cup final, etc.

Commented [JA33]: 'cultural' ??

Commented [DJ34R33]: Possibly, but more in the general sense of 'having something better to do with your time'

Commented [JA35]: Okay, could we say something like, in which there was a general sense that people could be doing something better with their time . 
value, indicating the social concerns around the new medium. These-Such concerns may well have been shared by those responsible for television at the BBC-and would have been addressed by them.

At the same time as these expressions of desire for a television that was educational and provide a 'window on the world', there were complaints about the snobbery of much television programming. These would merely have supported the findings of the BBC's audience research in autumn 1948 and December 1950, which reveals that television had been adopted across the social spectrum and was rapidly spreading 'downwards' through social and financial groupings. The enquiries also disclose that, 'given two neighbouring families of broadly similar economic status but of differing educational levels, it is the family where the educational level is the lower which is likely to acquire a television set first' (Silvey 1952, 33). Furthermore, it showed, 'that the "lower" groups tend to view more than the "higher"' (ibid., 36). Such a view of the television audience may well have contributed to the desire to avoid more formal experimental work, based on the argument that the audience would be unfamiliar or unwilling to engage with it, even unable to understand it.

As already noted, this led to what Bussell saw as 'the deliberate lowering of the intellectual standard of programmes, to cater for a new viewing public' (1952, 12). Bussell was not alone. None other than the Director-General (1944-52), Sir William Haley stated that television must 'fight against lowering of standards' and that 'television must not become a film industry. Television must remain civilized and adult' (quoted in Briggs, 1985, 940-942), revealing that film was perceived by some as having less cultural value, too entertainmentfocused, childish and uncivilised.

The issue of audience taste and BBC standards was central to the Corporation's approaches to its audience. The pure ideals of Reithian public service broadcasting to elevate the taste of the nation were challenged by the need to attract an audience in the first place. If
Commented [JA36]: Sorry, but the English goes off the rails at bit. Could you simplify, please.

Commented [DJ37R36]: Reworded

Commented [JA38]: Rewording has helped, but it still needs something else. In what way would they have to address this problem. 
no one bought television there would be no reason to fund its development. There was also the issue that the public were growing used to having choice. By 1950 the BBC were broadcasting three radio channels, but listeners could also tune into commercial stations from the continent broadcasting in English. Such channels were even available beyond the reach of their transmitters, as they were relayed by the wired relay rental services that provided a cheaper option for receiving radio than purchasing or renting a wireless set. As early as 1936, one listener complained to their MP: 'Why should we have programmes which the British Broadcasting Corporation pick for us? At present we have to rely on foreign stations to make wireless worth having' (Hansard, 1936, 967). Demonstrated here is the tension between the BBC's public service ideals and the desire of the potential audience for popular entertainment which underlie its programming from the introduction of the BBC to the present day.

\section{Conclusions}

While the threat of competition may have led the BBC Television Service to take more risks in opening up the intimate screen through the use of special effects and filmed inserts in productions such as those produced by Rudolph Cartier, in many ways these developments were simply following on from earlier experiments. However, when competition arrived in 1955 it was accompanied by a retrenching of a more conservative approach to television drama in order to appeal to a wider audience. There were clearly times when the ambitious experimentation of the producers of early British television outreached the technical capabilities of the medium, and further occasions when it stepped outside the ostensible taste of the audience. It is also clear that there were a number of tensions within television production, between different conceptions of what television should be in terms of style and how it should relate to its audiences. These were in turn influenced by the ongoing 
development of the technology of television, allowing for clearer images, faster switching between cameras, greater depth of field, etc. It is no surprise that there were various attempts to explore the use of this technology as a way to break out of the limitations of live studio drama. What is perhaps more surprising is how the audience was engaged with this process of experimentation. Attentive to the techniques and technologies of television, their interest is demonstrated by the press coverage of various productions' use of effects drawn upon throughout this article. Visual experimentation and effects were thus part of the ongoing interaction between the $\mathrm{BBC}$ and its audience, engaging with questions of taste and suitability, and the very purpose of television in entertaining or challenging, and in meeting the needs or desires of the audience. Those responsible for producing the BBC's television drama output had clearly been eager to break out of the temporal and spatial limitations of the live studio right from the beginning, but the challenge this posed to assumptions of television as an 'intimate' medium, and the relationship of special effects to structures of taste and interpretation are revealed here.

Derek Johnston is Lecturer in Broadcast Literacy at Queen's University. He mostly researches genre histories, particularly relating to fantastic genres and British television. He is author of Haunted Seasons: Television Ghost Stories for Christmas and Horror for Halloween (2015). His work has appeared in Science Fiction Film and Television; Networking Knowledge; The Routledge Companion to Science Fiction; British Science Fiction Film and Television: Critical Essays; It Came From the 1950s: Popular Culture, Popular Anxieties; Music in Science Fiction Television: Tuned to the Future and Directory of World Cinema: American Hollywood 2.

\section{Works Cited}


Note that many of the periodical articles used here came from the BBC's collection of press clippings held at the BBC Written Archives Centre. As complete pages are not held, page numbers are often absent and are noted as 'n.p.'.

Anon. 1937. ‘From Alexandra Palace: 1936-37’. Radio Times, 24 December, 28.

Anon. 1938. 'Miniature Drama: The Strange Magic of Television'. The Times, 17 January, n.p.

Anon. 1948a. 'Did You Ever Watch a Ghost Talking?' Sunday Graphic and Sunday News, 21 November, n.p.

Anon. 1948b. 'Radio Review'. Psychic News, 4 December, n.p.

Anon. 1950. 'My Teleview'. The Star, 15 November, n.p.

Anon. 1951. 'Helping the Scene Designer'. Radio Times, 29 June.

Anon. 1952a. 'Critic on the Hearth'. The Listener, 23 October: 694.

Anon. 1952b. ‘The Future of British Broadcasting’. Radio Times, 23 May, 2.

Barr, Robert. 1949. The Time Machine Camera Script, held at the BBC Written Archives Centre.

BBC PAB, Programmes as Broadcast records held at the BBC Written Archives Centre.

Below the Surface: A Naval Play. 1937. BBC.

Blithe Spirit. 1948. BBC.

Briggs, Asa, 1985. The BBC: The First Fifty Years. Oxford: Oxford University Press.

Bussell, Jan. 1952. The Art of Television. London: Faber and Faber.

Butcher, Cyril. 1950. 'Television'. The Sketch, 6 December, 569.

Caughie, John. 1991. 'Before the Golden Age: Early Television Drama'. In Popular Television in Britain: Studies in Cultural History, edited by John Corner, 22-41. London: British Film Institute. 
Chambers, Deborah. 2011. 'The Material Form of the Television Set: A Cultural History'. Media History 17 (4): 359-375.

Condemned to be Shot. 1939. BBC.

Cooke, Lez. 2013. Style in British Television Drama. Basingstoke: Palgrave Macmillan.

Cross, John Keir. 1950. BBC WAC: Camera Script, The Strange Case of Doctor Jekyll and Mr Hyde.

Darlington, W.A. 1938. 'A Televised Play: Ingenious Adaptation of “Doctor Knock”'. The Daily Telegraph, 14 January, n.p.

From Alexandra Palace: 1936-37. 1937. BBC.

Gentle People, The. 1949. BBC.

Hansard. 1936, BRITISH BROADCASTING CORPORATION. HC Deb 29 April vol 311 cc955-1040 (Hansard, Commons).

Here's Howard. 1951. BBC.

Holiday in Berlin. 1952. BBC.

Hunter, Alan. 1952. 'British Television'. Radio Times, 12 December, 5-6.

Jacobs, Jason. 2000. The Intimate Screen: Early British Television Drama. Oxford: Oxford University Press.

Johnston, Derek. 2009. 'Experimental Moments: R.U.R. and the Birth of British Television Science Fiction'. Science Fiction Film and Television 2 (2): 251-68.

Listener Research Section. 1937. BBC WAC, LR/1: Viewers and the Television Service: A Report of an Investigation of Viewers' Opinions in January 1937, 5 February.

Nineteen Eighty-Four. 1954. BBC.

Norden, Denis, Sybil Harper and Norma Gilbert, eds. 1985. Coming to You Live! Behind-thescreen Memories of Forties and Fifties Television, London: Methuen.

Once in a Lifetime. 1937. BBC. 
O’Sullivan, Tim. 2007. 'Researching the Viewing Culture: Television and the Home, 19461960’. In Re-Viewing Television History: Critical Issues in Television Historiography, edited by Helen Wheatley, 159-169. London: I.B.Tauris.

Passing Show, The. 1948-53. BBC.

Pudney, John, 1948. 'What Television Does To Us'. John Bull, 6 March, 8-11.

Quatermass Experiment, The. 1953. BBC.

Robson, Neil. 2004. 'Living Pictures Out of Space: The Forlorn Hopes for Television in Pre1939 London’. Historical Journal of Film, Radio and Television 24 (2): 223-232.

R.U.R. 1938. BBC.

Scanner, The. 1949. 'Talk of the Week'. Radio Times, 14 January, 24.

Silvey, Robert. 1952, 'Viewers, Viewing and Leisure’. BBC Quarterly VII (1): 31-40

Television Comes to London.1936. BBC.

Strange Case of Dr Jekyll and Mr Hyde, The. 1950. BBC.

Television Expert. 1947. 'Save Television from the Monopoly'. Daily Worker, 6 February,

$$
\text { n.p. }
$$

Time Machine, The. 1949. BBC.

Tristan and Isolde. 1938. BBC.

Turnaround. 1937. BBC.

Turner, W.J. 1938. ‘Televised Opera’. New Statesman and Nation, 5 February, n.p.

Tyrrell, Gerard. 1952. 'Some Notes on Playwriting for TV’. Writer, June. 8-11

Wrench, A.G. 1949.'Viewers Are Saying’. Radio Times, 4 February, 25.

\footnotetext{
${ }^{\text {i }}$ See Johnston (2009) for further details on the RUR productions.
} 